\title{
Nosocomios higienistas: el caso Florence Nightingale
}

\section{Nosocomial hygienists: Florence Nightingale case \\ Nosocomial higienistas: Florence Nightingale caso}

(Ponencia leída en la X Jornada Canaria de Historia de la Medicina, Colegio Oficial de Médicos de Santa Cruz de Tenerife, 1 de diciembre de 2012)

Dr. Francisco Javier Castro Molina

Enfermero de salud mental. Historiador del Arte.Complejo Hospitalario Universitario de Canarias. Servicio Canario de Salud. Cómo citar este artículo en edición digital: Castro Molina, F.J. (2013) Nosocomios higienistas: el caso Florence Nightingale. Cultura de lós Cuidados (Edición digital)17, 36. Disponible en: http://dx.doi.org/10.7184/cuid.2013.36.11

Correspondencia: Francisco Javier Castro Molina. Calle Las Trebinas 24-San Miguel de Geneto-San Cristóbal de La Laguna.38296-Santa Cruz de Tenerife. Correo electrónico: tenerifejavier@gmail.com Recibido: 11/02/2013.Aceptado: 23/06/2013

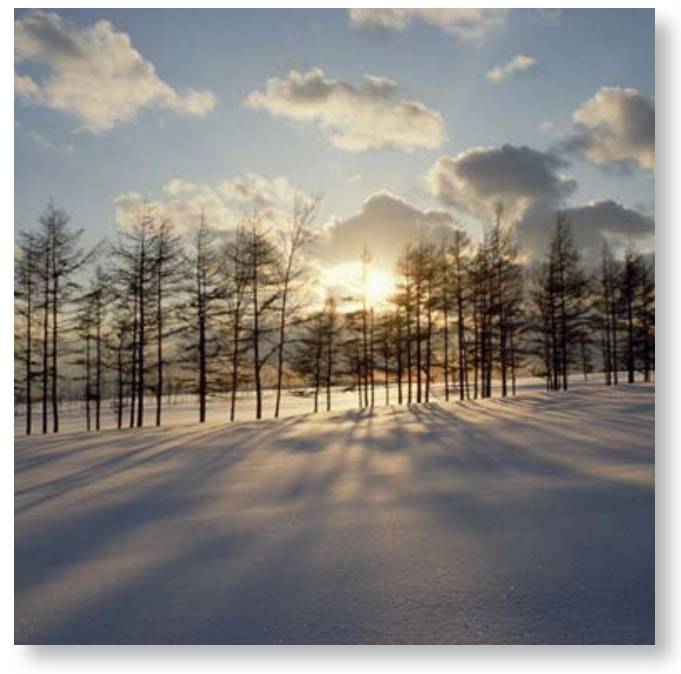

ABSTRACT

The dramatic changes that emerged after the start of the Industrial Revolution helped that solutions be sought repeatedly to different problems that were happening, one after another, as a result of overcrowding and sociopolitical and economic changes. Advances in the field of science, and particularly in the health sciences, were innumerable, settling in society marked by a concern to solve the problems of the lower classes. In the field of health, were gradually leaving positions anchored in the models based on the "miasma", moving to build on the model's hand microbial Pasteur and Lister. These findings were taken to the architecture gradually giving way to buildings that sought to maintain a hygienic environment that disease exiled inside the "walls of hospitals." Example of this struggle was conducted by the nurse Florence Nightingale, thanks to the observation and their knowledge acquired in the Kaiserswerth Deaconess Institute in Germany and the Maison de la Providence of the Sisters of Charity of Paris, managed to establish a set of guidelines that applied to the establishment managed, Scutari Hospital during the Crimean War.

Key words: Nightingale, hospital, hygiene, architecture, Scutari.

\section{RESUMO}

As dramáticas mudanças que surgiram após o início da Revolução Industrial ajudou a que as soluções ser procurado várias vezes para diferentes problemas que estavam acontecendo, um após o outro, como resultado de mudanças superlotação e sócio-político e econômico. Os avanços no campo da ciência, e em particular nas ciências da saúde, foram inúmeros, fixando-se em sociedade marcada por uma preocupação de resolver os 
problemas das classes mais baixas. No campo da saúde, foram deixando gradualmente posições ancoradas nos modelos baseados na “miasma”, movendo-se para construir na mão microbiana Pasteur do modelo e Lister. Estes resultados foram levados para a arquitetura gradualmente dando lugar a edifícios que procurou manter um ambiente higiênico que a doença exilado dentro das "paredes dos hospitais." Exemplo dessa luta foi conduzida pela enfermeira Florence Nightingale, graças à observação e os conhecimentos adquiridos no Instituto Deaconess Kaiserswerth na Alemanha e na Maison de la Providence das Irmãs da Caridade de Paris, conseguiu estabelecer um conjunto de diretrizes que se aplicam ao estabelecimento gerenciado, Scutari Hospital durante a Guerra da Criméia.

Palavras-chave: Rouxinol, hospital, higiene, arquitetura, Scutari.

\section{RESUMEN}

Los impresionantes cambios surgidos tras el inicio de la Revolución Industrial ayudaron a que de manera reiterada se buscaran soluciones a los diferentes problemas que se sucedían, uno tras de otro, como resultado del hacinamiento y las modificaciones sociopolíticas y económicas. Los avances en el campo de la ciencia, y en particular en las ciencias de la salud, fueron innumerables, estableciéndose en la sociedad una preocupación marcada por solucionar los problemas de las clases más desfavorecidas. En el campo de la sanidad, progresivamente se fueron dejando atrás posturas ancladas en los modelos basados en los «miasmas», para pasar a fundamentarse en el modelo microbiano de la mano de Pasteur y Lister. Estos descubrimientos fueron trasladados a la arquitectura progresivamente, dando paso a edificios que bus- caban mantener unas condiciones higiénicas adecuadas que exiliaran las enfermedades del interior de los «paramentos de los hospitales». Ejemplo de esta lucha fue la llevada a cabo por la enfermera Florence Nightingale, que gracias a la observación y a sus conocimientos adquiridos tanto en el Instituto de Diaconisas de Kaiserswerth en Alemania como en la Maison de la Providence de las Hermanas de la Caridad de París, logró establecer una serie de pautas que aplicó al establecimiento que gestionó, el Hospital Scutari, durante la Guerra de Crimea.

Palabras clave: Nightingale, hospital, higiene, arquitectura, Scutari.

El siglo XIX vino marcado por tres hechos trascendentales para la disciplina médica y la Humanidad. La publicación en 1859 de las teorías evolutivas de Charles Darwin reavivó el interés por la ciencia de la anatomía y la fisiología comparadas. A ello, se unieron los experimentos sobre el cruce de plantas del biólogo austriaco Gregor Johann Mendel que tuvieron un efecto semejante, ya que estimularon y favorecieron los estudios sobre la genética humana y la herencia.

El segundo suceso fue el estudio del químico y microbiólogo francés Louis Pasteur sobre la fermentación que acabó con el concepto de la generación espontánea y fomentó un marcado interés en la teoría de que ...la enfermedad es el resultado de un contagio específico. A este hecho se unió el trabajo inédito sobre la fiebre puerperal del médico estadounidense Oliver Wendell Holmes y del obstetra húngaro Ignác Fülöp Semmelweis. Demostraron que la elevada tasa de mortalidad en mujeres después del parto era debida a agentes infecciosos transmitidos por las manos contaminadas de los médicos. El último, y de semejante calado 
que las contribuciones de Pasteur, fueron las del médico y bacteriólogo alemán Robert Koch en el campo de la bacteriología; el desarrollo de este campo se considera el avance individual más importante de la medicina ${ }^{1}$.

Todos los progresos realizados en el diagnóstico, tratamiento de la enfermedad y de los métodos quirúrgicos durante el siglo XIX, fueron el resultado de los descubrimientos del siglo anterior. Un ejemplo claro fue el desarrollo de los procedimientos diagnósticos de las enfermedades torácicas realizadas por el médico austriaco Leopold Auenbrugger, para lo que empleó el método de la percusión, descrito por primera vez en 1761. Su trabajo, sin embargo, fue ignorado hasta 1808 cuando se publicó una traducción francesa por el médico personal de Napoleón ${ }^{2}$.

Un importante avance vino marcado por los nuevos métodos de diagnóstico de enfermedades que favoreció el etiquetado de muchas de ellas: el médico Thomas Addison descubrió el trastorno de las glándulas suprarrenales; Richard Bright diagnosticó la nefritis; Tomas Hodgkin describió una enfermedad maligna del sistema linfático; el cirujano y paleontólogo James Parkinson describió la enfermedad crónica del sistema nervioso; y el médico irlandés Robert James Graves diagnosticó el bocio exoftálmico tóxico ${ }^{3}$.
Gracias a estos avances, en pocos años, se lograron aislar y concretar las causas de procesos y enfermedades como el carbunco, la difteria, la tuberculosis, la lepra o incluso la temida peste ${ }^{4}$. En el ámbito del combate contra las infecciones que causaban estragos en la población, mediante la prevención se superaron grandes escollos que producían numerosas muertes y dejaban secuelas de considerable importancia en los individuos. El ginecólogo alemán Karl Sigismund Franz Credé desarrolló un método que consistía en administrar gotas de una solución antiséptica de nitrato de plata en los ojos de los neonatos para prevenir la oftalmia gonocócica, de tal eficacia que se ha continuado empleando hasta la actualidad. También destaca el método de inmunización de Pasteur mediante el cual se inyectaba virus atenuados y que se empleó con éxito en el tratamiento de la rabia. Además se avanzó en el campo de la investigación del sistema inmunitario, cuando el bacteriólogo ruso Iliá Mechnikov fue el primero en describir los fagocitos destructores de bacterias y otros elementos extraños al organismo ${ }^{5}$. En 1898 el médico británico Ronald Ross demostró el papel del mosquito como transmisor del parásito de la malaria y dos años después, en 1900, el médico, cirujano y bacteriólogo del ejército estadounidense Walter Reed y sus colaboradores, tras trabajar

\footnotetext{
${ }^{1}$ Mendoza-Vega, J. M. D. (2003). Lecciones de Historia de la Medicina. Segunda edición aumentada y corregida. Centro Editorial Universidad del Rosario, Bogotá, Colección Ciencias de la Salud (Libro).

2 Tendría que esperarse hasta 1819, para que el médico francés René Théophile Hyacinthe Laënnec inventara el fonendoscopio, instrumento muy utilizado por los profesionales sanitarios hasta la actualidad.

${ }^{3}$ Jaramillo Antillón, J. (2005). Historia de la filosofía de la medicina. Editorial Universidad de Costa Rica, San José- Costa Rica (Libro).

${ }^{4}$ Ibidem. Entre los primeros bacteriólogos que destacaron en este momento, se encontraba el fisiólogo alemán Edwin Theodore Albrecht Klebs, quien logró aislar el bacilo causante de la difteria e investigó la bacteriología del ántrax y la malaria. A esto se unieron los trabajos llevados a cabo por el bacteriólogo alemán Friedrich August Johannes Löffler, que descubrió la bacteria causante de la gonorrea, y los del médico noruego Gerhard Henrik Hansen, que logró hallar el bacilo causal de la lepra.

${ }^{5}$ Sánchez González, M. A. (2002). Historia, teoría y método de la medicina: introducción al pensamiento médico. Editorial Masson, Barcelona (Libro).

Dentro de estas líneas de investigación debe incluirse la del bacteriólogo alemán Emil Adolph von Behring quien desarrolló sueros inmunizantes contra la difteria y el tétanos.
} 


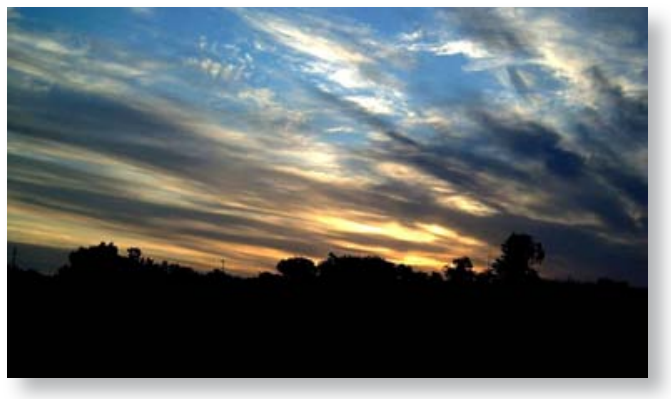

sobre una sugerencia realizada por el biólogo cubano Carlos Juan Finlay, demostraron que el mosquito era el vector de la fiebre amarilla ${ }^{6}$.

Debe destacarse que todos estos adelantos en la Microbiología favorecieron considerablemente a la Cirugía, que se benefició de manera significativa de la teoría de los gérmenes. El cirujano británico y biólogo Joseph Lister adoptó el uso del ácido carbólico como agente antiséptico con resultados importantes en el descenso de la mortalidad debida a la infección de las heridas. Las pruebas y estudios aportados por Lister, que demostraban que las bacterias se transmiten a través del aire, permitieron más tarde, comprender dicha transmisión por medio de las manos y los instrumentos (fómites), cuya esterilización introdujo la era de la cirugía aséptica, a lo que se unió el descubrimiento y empleo de los anestésicos, evolucionando progresivamente hasta lo que conocemos actualmente ${ }^{7}$.

Con el progreso de la física y la química, se produjo un enorme avance de la fisiología durante el siglo XIX. Entre los más conocidos fisiólogos de este periodo se encuentra el químico alemán Justus von Liebig, que desarrolló los métodos analíticos de la química orgánica y la química de los alimentos, el llamado metabolismo. A ellos se unió el trabajo del histólogo español Santiago Ramón y Cajal que contribuyó al conocimiento moderno de la estructura y función del sistema nervioso ${ }^{8}$. Además, el fisiólogo francés Claude Bernard, fundador de la medicina experimental, realizó importantes descubrimientos sobre las funciones del páncreas, el hígado y el sistema nervioso simpático que revolucionaron la concepción que existía hasta este momento sobre estos órganos del cuerpo humano. En 1803, el biólogo estadounidense John Richardson Young describió el proceso de la formación del ácido en la digestión gástrica. Años más tarde, el cirujano estadounidense William Beaumont publicó sus interesantes estudios sobre los jugos gástricos y la fisiología de la digestión basados en la observación de un paciente que padecía de una fístula gástrica. Otro destacado hallazgo fue el trabajo de Bernard sobre la interacción del aparato digestivo y el sistema vasomotor, que se centraba en el control del tamaño de los vasos sanguíneos, y que sirvió de base para el desarrollo de la teoría del reflejo condicionado, base posterior del conductismo defendida por el fisiólogo ruso Iván Petróvich Pavlov9

\footnotetext{
${ }^{6}$ Ibidem.

${ }^{7}$ Molina Jiménez, I.; Acuña Acosta, V. H.; Gutiérrez, J. M.; Jaramillo Antillón, J.; Páez, J.; Jiménez, M. (2004). Balances del siglo XX: historia, microbiología, medicina y física. Editorial de la Universidad de Costa Rica, Escuela de Estudios Generales (Sección de Historia de la Cultura), Serie Cuadernos de Historia de la Cultura n 11, San José-Costa Rica (Libro).

${ }^{8}$ Por otro lado, el físico y fisiólogo alemán Hermann Ludwig Ferdinand von Helmholtz, quien inventó el oftalmoscopio y el oftalmómetro, investigó la velocidad de los impulsos nerviosos y de los procesos reflejos, y llevó a cabo estudios relevantes sobre óptica y acústica.

${ }^{9}$ Sánchez González, M. A. (2002). Opus cit, (Libro).

Entre los otros fisiólogos del siglo XIX destacan el médico franco-estadounidense y fisiólogo Charles Edouard Brown-Séquard, que investigó la función de varias glándulas del sistema endocrino, y Carl Friedrich Wilhelm Ludwig, fisiólogo alemán que exploró la actividad cardiaca y renal.
} 
Una ayuda de incalculable valor diagnóstico fueron los rayos $\mathrm{X}$, hallados de forma accidental por el físico alemán Wilhelm Conrad Roentgen y que permitieron grandes avances en esta parte de la disciplina médica; a ello se unió el descubrimiento del radio por los físicos franceses Pierre y Marie Curie con el que se pudieron tratar algunas formas de cáncer. En el capítulo de la ginecología, el médico y cirujano estadounidense, Ephraim McDowell, realizó la primera extirpación quirúrgica de un tumor de ovario. Otro logro destacado fue el del ginecólogo James Marion Sims quien salvó la vida de muchas mujeres con la corrección quirúrgica de la fístula vésicovaginal realizada por primera vez en $1845^{10}$.

En el campo de la Enfermería, éste es el momento en el que se produce una modificación considerable en las competencias de los practicantes con la creación de la titulación de cirujano dentista. Además, se establecen para los estudios de comadrona, una serie de requisitos considerablemente estrictos: haber aprobado la primera enseñanza elemental; tener veinte años cumplidos, y ser viudas o casadas. En el caso de estás últimas, las casadas, tenían que presentar un documento donde el marido las autorizase a trabajar, y poseer certificado de buenas costumbres expedido por su párroco. Este nuevo reparto de tareas constituyó una desestructuración de las actividades de enfermería que benefició considerablemente tanto a practicantes como a comadronas que llevó aparejado una disminución de la calidad de la asistencia hasta llegar a niveles en los que estas tareas eran desempeñadas por mujeres que no sabían leer ni escribir, carentes de preparación académica alguna $^{11}$.

En los hospitales civiles donde no existía una gestión eclesiástica, el panorama era considerablemente deprimente, a diferencia de los religiosos, donde su situación era algo mejor, ayudada por la formación suministrada por las monjas veteranas que se dedicaban a formar a las enfermeras nuevas ${ }^{12}$. Concepción Arenal en su reforma del sistema penitenciario y sanitario señaló la necesidad de crear escuelas para formar enfermeras como antes, pero este intento no tuvo éxito, lo que ocasionó que la profesión no fuera de elección a la hora de incorporarse al mundo laboral, ya que entrañaba una mala consideración a nivel social y profesional ${ }^{13}$.

En este contexto propicio a los cambios, surge la figura de Florence Nightingale, quien trabajó en el Instituto de Diaconisas de Kaiserswerth en Alemania y en la Maison de la Providence de las Hermanas de la Caridad de París $^{14}$, donde se nutrió, permitiéndole adquirir la formación que llevó al Hospital de Scutari, en Turquía, durante la Guerra

\footnotetext{
${ }^{10}$ Mendoza-Vega, J. M. D. (2003). Opus cit, p. 195-207.

El médico danés Niels Ryberg Finsen desarrolló una lámpara de rayos ultravioletas, hecho que mejoró el pronóstico de algunas enfermedades de la piel.

${ }^{11}$ García Martín-Caro, C. y Martínez Martín, M. L.. (2007). Historia de la enfermería: evolución histórica del cuidado enfermero. Editorial Elsevier, Madrid (Libro).

Las enfermeras eran relegadas a tareas de sirvienta y tenían sueldos muy inferiores a los de los enfermeros.

${ }^{12}$ Castro Molina, F. J. (2012). Arquitectura y Medicina en Canarias. Dispositivos asistenciales y recursos sanitarios en Tenerife (s. XVI-XX). Tesis doctoral-Universidad de La Laguna bajo la dirección de María Isabel Navarro Segura y Jesús Pérez Morera; La Laguna: [s.n.], (Tesis doctoral).

${ }^{13}$ Salas Iglesias, P.M. (2012). El reformismo social y sanitario de Concepción Arenal. Una contribución a la identidad de la enfermería contemporánea. Editorial Club Universitario, Alicante (Libro).

${ }^{14}$ Castro Molina, F. J.; Rodríguez Gómez, J. A. (2012). Uniformes e imagen social de los cuidadores profesionales. Colección Centenario del Ilustre Colegio Oficial de Enfermería de Santa Cruz de Tenerife. Ilustre Colegio Oficial de Enfermería de Santa Cruz de Tenerife, Santa Cruz de Tenerife (Libro).
} 


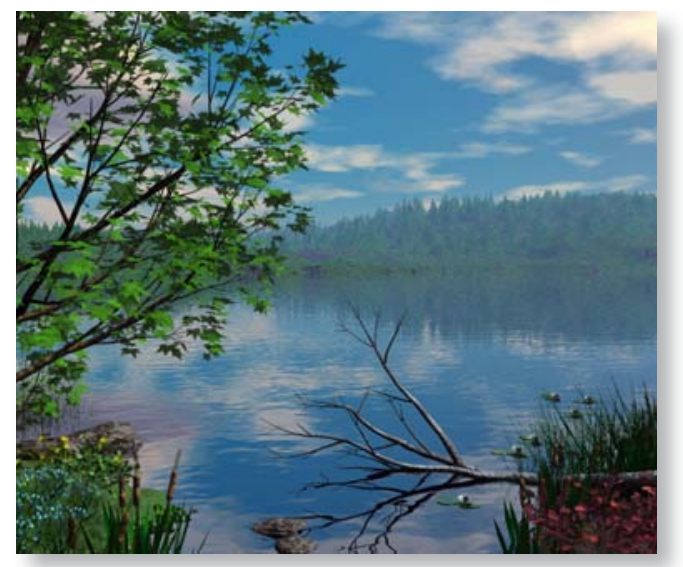

de Crimea, como superintendente de un grupo de enfermeras, en octubre de $1854^{15}$. Tras observar la preparación que tenían los soldados que estaban encargados del cuidado de los enfermos, a la vuelta de la Guerra de Crimea utilizó su influencia para abogar a favor de la formación de los soldados y los médicos militares británicos. Pese a que las competencias de Florence cuando viajó a Crimea eran limitadas, en el momento más crítico de la guerra destacó la falta de experiencia práctica de muchos de los jóvenes cirujanos, para lo que propuso que recibieran lecciones sobre patología y cuestiones afines sin esperar a que acabara el conflicto ${ }^{16}$. Más tarde, este interés de Florence por este tema, se vería reconocido por la Comisión Real sobre Sanidad Militar, que hizo de la instrucción sanitaria de sus miembros una de sus cuatro áreas de estudio. Además, entre sus actividades, se incluyó la realización de una relación de pruebas sobre la «mala administración de los hospitales», a lo que se unieron diferentes estadísticas que abordaban la mortalidad; y elaboró una serie de planes educativos que centraban su atención en la sanidad, la eficacia y la administración de los hospitales militares británicos ${ }^{17}$. Sus importantes aportaciones favorecieron la creación de la primera Escuela de Medicina Militar del Reino Unido en Fort Pitt en 1860, donde se estableció una enseñanza orientada hacia el ejército, oficiales y tropa ${ }^{18}$.

Tras su regreso a Inglaterra aquejada de una grave enfermedad, destacó, entre otras cosas, por su formación en matemáticas y estadística, situación que demostró al hacer públicos los resultados de las actuaciones acometidas en Turquía. A ello se le unió la publicación de sus conocidas Notas sobre la enfermería en 1859, cuyo texto sirvió como referente en la escuela de enfermeras que fundó con la ayuda de los donativos de civiles y soldados, formando "profesionales de los cuidados» para hospitales, domicilios y enseñanza.

\footnotetext{
${ }^{15}$ Ibidem.

Instruyó a toda prisa 38 enfermeras dispuestas a ir a un hospital de guerra en la otra punta del mundo, donde atendieron entre 3.000 a 4.000 soldados heridos e ingresados en condiciones higiénicas deplorables. Los mandos militares a cargo del destacamento mostraron una actitud de rechazo, ya que no estaban nada predispuestos a ser mandados por una civil que encima era mujer. El índice de mortalidad que se estimaba por encima del $40 \%$ logró disminuirlo casi un $3 \%$ a base de aplicar mejoras en la calidad asistencial, tanto médica como humana de los pacientes.

Demostró, durante su estancia en este hospital, dotes de administradora que con los recursos básicos organizó salas de hospitalización limpias y confortables, asistencia de enfermería adecuada, cocinas eficientes, salas de recreo y medios para distraer a los enfermos, lavandería... Debe destacarse la situación, que posteriormente la ha identificado, que fue el uso de la lámpara durante sus rondas nocturnas por el hospital para ver el estado de los pacientes más graves. Organizó distintos hospitales de la zona hasta que enfermó gravemente y tuvo que volver a Inglaterra en 1856.

${ }^{16}$ Se instaló un laboratorio de patología en el Hospital de Scutari como resultado de la importancia que le dio Florence Nightingale a esta área.

${ }^{17}$ Este ideario formó parte de su obra más conocida, Notas de Enfermería, donde recoge gran parte de la experiencia que adquirió durante su estancia en la Guerra de Crimea, donde sus fascinadores razonamientos fueron empleados por médico y cirujanos.

${ }^{18}$ Mostró ideas considerablemente avanzadas para su época. Planteó formar al soldado en diferentes áreas, instruyéndolo en hábitos saludables, como por ejemplo la ingesta excesiva de alcohol, o en cuestiones como la prostitución.
} 
Pero, ¿cuál fue la influencia de Nightingale en la arquitectura hospitalaria del momento? ¿Estableció una nueva forma de ver el «espacio asistencial»? No es de sorprender que las mayores mejoras se logren durante las contiendas bélica, momento en el que se persigue la eficiencia económica. Para poder atender a las tropas inglesas presentes en la Guerra de Crimea, Isambard Brunel diseñó un hospital en barracas en 1855, que se instaló en el pueblo turco de Renkioi, por las características tan favorables que presentaba la zona: agua potable, proximidad al mar, ligeramente elevado, y dotado de un suelo poroso $^{19}$. Como solución arquitectónica se empleó un modelo de cabaña prefabricada de madera donde se le dio prioridad a la economía y a su fácil transporte. Se pretendía la autosuficiencia de las instalación, creando interiormente dos espacios claramente definidos: dos salas para los enfermos, y un área destinada al personal sanitario, que estaba conformada por: local para enfermeras, local para médicos, almacén de pequeñas dimensiones, cuarto de baño, retrete y lavabo. El modelo que se seleccionó contaba con una óptima ventilación que se lograba mediante la abertura de ventanas a lo largo de todo el alero y ventanas estrechas en el paramento opuesto, y protección solar mediante sistema de persiana que facilitaban la circulación del aire. Bajo el cerramiento superior, se dispuso la instalación de un ventilador que proporcionaba un flujo artificial adicional, logrando así que todo el aire introducido en el barracón saliera al exterior mediante aperturas ubicadas bajo las mesas y las dos filas de camas dispuestas en las salas ${ }^{20}$.

Entre julio de 1855 y marzo de 1856, la población enferma alojada en el nosocomio creció, de 300 a 2.200, lo que obligó a adaptarse a las nuevas demandas: se dispusieron cabañas para el personal de enfermería con características idénticas, lavanderías próximas a los nacientes, cocinas independientes para abastecer de alimentos por cada 500 enfermos, servicios sanitarios anexos a las salas colocadas sobre una acequia principal de drenaje, calefacción de salas mediante caldera de mínimas dimensiones ubicadas sobre la lumbre de cada sala, e iluminación artificial con velas dentro de lámparas especiales. Mientras el Hospital de Renkioi, con sus 2.200 enfermos presentaba un mortalidad del 3\%, el de Scutari, con 2.500 pacientes presentaba la considerable cifra del 42.7\%. Scutari era el Hôtel Dieu de la enfermera Florence Nightingale y su efecto sobre ella era comparable al de París sobre Jaques-René Tenon. Con la misiva de igualdad en la "actividad cuidadora» entre enfermeros y enfermeras, Nightingale llegó con una treintena de «cuidadoras profesionales», unas treinta y ocho, que pusieron su empeño para dejar atrás los nefastos resultados que habían sesgado la vida a tantos soldados en Scutari. Describía el lugar como sucio y habitado por roedores, donde «se flotaba en un mar de basura acumulada en las alcantarillas que había debajo y que se había desmoronado», facilitando la aparición de la fiebre de hospital y la disentería ${ }^{21}$. Esta situación ocasionó que, a

\footnotetext{
${ }^{19}$ Castro Molina, F. J; Castro González, Ma P; Megias Lizancos, F; Martín Casañas, F. V; Causapié Castro, A. (2012). Arquitectura hospitalaria y cuidados durante los siglos XV al XIX. Cultura de los Cuidados. (Edición digital) 16, 32. Disponible en: http:// dx.doi.org/10.7184/cuid.2012.32.05.

${ }^{20}$ Brunel, I. (1870). The life of Isambard Kingdom Brunel, civil engineer. Longmans, Green \& Co., Londres (Libro). Los materiales empleados para su construcción fueron madera recubierta de planchas delgadas de estaño (aislamiento térmico) $y$ forrado interior con material refractario.

${ }^{21}$ Woodham-Smith, C. (1992). Florence Nightingale. Constable, Londres (Libro).

Pevsner, $N$ (1979). Historia de las tipologías arquitectónicas. Gustavo Gili, Barcelona (Libro).
} 
partir de ese momento, en su ideario siempre estuviera presente un marcado interés por la limpieza, la eficiencia y la adecuación de las instalaciones para drenaje.

A su regreso a Inglaterra, el "Ángel de Crimea» centró todos sus esfuerzos en publicar dos libros: Notas sobre hospitales (1858) y el ya nombrado, Notas sobre la enfermería (1859). Ambas obras, unidas al prestigio adquirido durante la Guerra de Crimea, ayudaron a «idolatrar la labor de Nightingale», convirtiéndola en una experta asesora para nosocomios militares y civiles, aunque su lugar estuvo en segunda línea, propio de una mujer inserta en la sociedad inglesa de ese momento. Pesó considerablemente dentro de su ideario el concepto de «sala operativa» que había adquirido gracias a su experiencia personal y a la visita tanto a hospitales ingleses civiles de Dublín, Londres y Edimburgo, como a hospitales militares y navales. Además conoció otros nosocomios franceses, alemanes, italianos, holandeses, turcos y egipcios, de los que destacó las barracas de Renkioi, el hospital Laribosière y el hospital militar de Vincennes. En contraposición, recogió en sus Notas sobre hospitales el horrible ejemplo del Royal Victoria de Netley, un pasillo-hospital de semejantes características al hospital de Bamberg, caracterizado por camas en filas paralelas a las ventanas y construcciones privadas entre cada dos salas. Los revolucionarios planteamientos de Nightingale, se centraban en el entorno sanitario y la facilidad de observaciónsupervisión, que chocaban con el plano tipo corredor y con las dobles salas adosadas tan apreciadas en este momento ${ }^{22}$.
«Miasmátista acérrima», Nightingale desechaba la idea de una posible existencia de gérmenes que causaran enfermedades, estableciendo una rápida putrefacción de las materias orgánicas, que junto al vapor de agua, eran exhaladas por los individuos tanto enfermos como sanos. Estas «exhalaciones mórbidas» debían ser exiliadas, rápida $\mathrm{y}$ eficazmente, de las salas donde se atendía a los pacientes, proporcionando aire puro mediante sistemas constructivos que portaran un basamento de hormigón o un abovedado, aislado de las salas, junto a patios abiertos de muros bajos carentes de vegetación que propiciara la penumbra. El nosocomio debía articularse a partir de varios edificios exentos dispuestos en superficies grandes, en dos alturas como máximo, cuyas características facilitaran el soleamiento y ventilación en todo momento. Tollet aboga por estos planteamientos, como nos hace llegar en alguno de sus discursos: es falto de toda lógica construir grandes edificios de mucha altura, simplemente para halagar el mal gusto de los Comités o de los Gobernantes ${ }^{23}$. Para departamentos tales como la cocina, lavandería y oficinas destinadas a la administración, se propusieron edificios anexos: el primero debía estar centralizado, el segundo alejado de las salas donde se alojara a los pacientes, y el último, próximo para favorecer una adecuada supervisión.

Esta sala destinada a enfermos, que en un primer momento se denominó «Sala Nightingale», era el producto de la aplicación del pensamiento y la experiencia de los conocimientos adquiridos por las corrientes

\footnotetext{
${ }^{22}$ Las dobles salas adosadas no permitían una adecuada observación de los pacientes, a lo que se le unía la ubicación de ventanas $y$ puertas que interferían, en el modelo de plano tipo corredor, en la ventilación natural de la sala.

${ }^{23}$ Tollet, C. (1894). Les hospitaux Modernes XIXme siècle. Description des principaux hopitaux français et étrangers: les plus récemment édifiés divisés en dix sections par contrées: études comparatives sur leurs principales conditions d'etablissement: mémoires divers se rapportant à l'hygiène et à l'économie des constructions hospitalières. Chez L'Auteur, París (Libro).
} 
higienistas a lo largo del siglo XIX, que se centraban en un reconocimiento empírico de la relación existente entre enfermedad y suciedad. Florence, defendía una sala articulada a partir de vanos dispuestos a lo largo de los paramentos, con mayor espacio para los enfermos en la entrada, y un habitáculo destinado a la jefa de enfermeras en la cabecera de la sala, con ventana panorámica orientada hacia ésta que se enfrentaba a otra de semejantes condiciones abierta al exterior; en la parte opuesta se disponía un local con fregadero para el menaje de mesa ${ }^{24}$. Contraria a esta habitación, a ambos lados del pasillo, un baño con un aseo-retrete.

El edificio en cuestión, «construido de aire puro», idealmente debía presentar entre 35-39 metros de largo por 9 de ancho, techo entre 4.80 y 5.10 metros, y las ventanas, de dimensiones considerables, a 0.30 metros del cerramiento superior y el alfeizar entre 0.60 y 0.90 metros del suelo. El calor de la estancia se lograba mediante chimenea ubicada en el centro, lo que favorecía el bienestar de los 32 enfermos alojados en la sala. Este número de aquejados era el idóneo para la correcta supervisión de la enfermera, facilitando las condiciones higiénicas, además de establecer un «territorio individual» de unos 2.50 por 3.60 metros para cada uno de los alojados. Su disposición espacial debería permitir un aprovechamiento del mayor número de horas solares, donde el eje de la sala debería ser norte-sur, consiguiendo que en el paramento se destinara un tercio de su superficie para las ventanas, logrando así una disposición de un vano por cada dos camas. Para el revestimiento interior se empleó roble lacado para el suelo, paredes de hormigón pulimentado carente de capacidad absorbente, de color rosa preferentemente, a los que se unían los colores de las flores y plantas que la decoraban, ubicadas en la zona media de la sala junto a motivos decorativos, seculares o profesos, e instrumentos, como el piano, para los actos religiosos.

Esta propuesta, pese a que se generalizó en los Estados Unidos de Norteamérica, progresivamente fue sustituyéndose por modelos diferentes, conservándose tan solo en Inglaterra, como bien se demuestra en las salas, escasamente modificadas del hospital St. Thomas de Londres. Miss Nightingale logró desarrollar plenamente sus ideas en el Herber Hospital entre 1859 y 1864 . Dispuso las salas, de 26 camas, en tres niveles, hasta un total de 658, cuyos pabellones se interconectaban a partir de un corredor central, de única altura, logrando evitar la penumbra que hubiera provocado un edificio elevado, estableciendo una planta en «espina de pescado», que sirvió de modelo a otras, como la empleada para el Hospital Militar de Santa Cruz de Tenerife. Los pabellones, paradójicamente, presentaban una orientación muy distante al tan admirado hospital Laribosière, estableciendo un lenguaje arquitectónico con marcado gusto francés para el edificio destinado a los servicios administrativos. Tras un «visible vestido neogótico», en su interior se abogó por un mantenimiento de la sala larga-exigencias sanitarias con igual habilidad que la empleada para la sala larga-capilla medieval.

Esta novedosa forma de articular el nosocomio se repitió por numerosas ciudades europeas y estadounidenses, como el hospital Moses Taylor de Scratosn en Pennsylvania. Otros como el Hospital Civil de Antwerp con 388 camas, construido en 1878, el plano básico cambia completamente el esquema.

Finalmente, en Francia, la Sala Tollet se ${ }^{24}$ Florence Nightingale pone énfasis en el empleo de platos de cristal o loza, abandonando el uso de materiales tales como el estaño
para este tipo de utillaje. 
convirtió en un referente. El proyecto estaba desarrollado a partir del modelo establecido por la Academia Francesa y el plano de la sala doble de Tenon, al que se le adicionó un balaustre en el margen de los lados más largos, formando habitaciones de dos camas para aislamiento. Mientras, el primer nivel empleaba los extremos para alojar comedores o convalecientes, presentando un uso de recreo o ventilatorio. Ésta última era lograda gracias a conductos que tomaban del basamento aire para introducirlo posteriormente en las salas a través del suelo, que posteriormente salía al exterior mediante un tiro que se ayudaba de la distribución de la cubierta superior en arcos apuntados, que conectaban con chimeneas con caperuza ${ }^{25}$.

\section{BIBLIOGRAFÍAS}

- Brunel, I. (1870) The life of Isambard Kingdom Brunel, civil engineer. Longmans, Green \& Co., Londres.

- Castro Molina, F. J. (2012) Arquitectura y Medicina en Canarias. Dispositivos asistenciales y recursos sanitarios en Tenerife (s. XVI-XX). Tesis doctoral-Universidad de La Laguna bajo la dirección de María Isabel Navarro Segura y Jesús Pérez Morera; La Laguna: [s.n.].

- Castro Molina, F. J.; Rodríguez Gómez, J. A. (2012) Uniformes e imagen social de los cuidadores profesionales. Colección Centenario del Ilustre Colegio Oficial de Enfermería de Santa Cruz de Tenerife. Ilustre Colegio Oficial de Enfermería de Santa Cruz de Tenerife, Santa Cruz de Tenerife.

- Castro Molina, F. J; Castro González, Ma P; Megias Lizancos, F; Martín Casañas, F. V; Causapié Castro, A. (2012) Arquitectura hospitalaria y cuidados durante los siglos XV al XIX. Cultura de los Cuidados. (Edición digital) 16, 32. Disponible en: http://dx.doi.org/10.7184/cuid.2012.32.05.

- Fernández Caro, Dr. (1891) Hospitalización. Sociedad Española de Higiene-Tema discutido durante los Curso Académico 1890-1891. Establecimiento tipográfico de
Enrique Teodoro, Madrid.

- García Martín-Caro, C. y Martínez Martín, M. L. (2007)

Historia de la enfermería: evolución histórica del cuidado enfermero. Editorial Elsevier, Madrid.

- Jaramillo Antillón, J. (2005) Historia de la filosofía de la medicina. Editorial Universidad de Costa Rica, San José- Costa Rica.

- Mendoza-Vega, J. M. D. (2003) Lecciones de Historia de la Medicina. Segunda edición aumentada y corregida. Centro Editorial Universidad del Rosario, Bogotá, Colección Ciencias de la Salud.

- Molina Jiménez, I.; Acuña Acosta, V. H.; Gutiérrez, J. M.; Jaramillo Antillón, J.; Páez, J.; Jiménez, M. (2004) Balances del siglo XX: historia, microbiología, medicina y física. Editorial de la Universidad de Costa Rica, Escuela de Estudios Generales (Sección de Historia de la Cultura), Serie Cuadernos de Historia de la Cultura $n^{\circ}$ 11, San José-Costa Rica.

- Pevsner, N (1979) Historia de las tipologías arquitectónicas. Gustavo Gili, Barcelona.

- Salas Iglesias, P. M. (2012). El reformismo social y sanitario de Concepción Arenal. Una contribución a la identidad de la enfermería contemporánea. Editorial Club Universitario, Alicante.

- Sánchez González, M. A. (2002) Historia, teoría y método de la medicina: introducción al pensamiento médico. Editorial Masson, Barcelona.

- Thomson, J.; Goldin, G. (1975) The Hospital: a Social and Architectural History. New Haven and London. Yale University Press.

- Tollet, C. (1894) Les hospitaux Modernes XIXme siècle. Description des principaux hopitaux français et étrangers: les plus récemment édifiés divisés en dix sections par contrées: études comparatives sur leurs principales conditions d’etablissement: mémoires divers se rapportant à l'hygiène et à l'économie des constructions hospitalières. Chez L'Auteur, París.

- Woodham-Smith, C. (1992) Florence Nightingale. Constable, Londres .

\footnotetext{
${ }^{25}$ Fernández Caro, Dr. (1891) Hospitalización. Sociedad Española de Higiene-Tema discutido durante los Curso Académico 1890 1891. Establecimiento tipográfico de Enrique Teodoro, Madrid (Libro).
} 